\title{
PERSPECTIVAS DE INSERÇÃO SOCIAL DE TRABALHADORES ORIUNDOS DE BANGLADESH E DO SENEGAL NA COMUNIDADE RONDONENSE
}

\author{
PERSPECTIVES OF SOCIAL INTEGRATION OF WORKERS \\ ARISING FROM BANGLADESH AND SENEGAL IN \\ RONDONENSE COMMUNITY
}

\author{
Paulo César da Silva llha \\ Faculdade de Ensino Superior de Marechal Cândido Rondon - PR - Brasil \\ Valdir Antonio Galante \\ Universidade Estadual do Oeste do Paraná - Toledo - PR - Brasil \\ Manoel João Ramos \\ Faculdade de Ensino Superior de Marechal Cândido Rondon - PR - Brasil \\ Moacir Piffer \\ Universidade Estadual do Oeste do Paraná - Toledo - PR - Brasil
}

\begin{abstract}
Resumo: Este estudo apresenta uma análise de como os ambientes institucional, organizacional e econômico podem influenciar na inserção social de trabalhadores estrangeiros na comunidade rondonense. Para isso, aplicou-se a Análise Estrutural Prospectiva, um método sob a forma matricial de análise das relações entre as variáveis constitutivas do sistema estudado e aquelas que pertencem ao seu contexto explicativo. Os resultados sugerem que existe uma forte influência do ambiente institucional e econômico no que diz respeito às políticas de imigração entre os países e a inserção social dos imigrantes na comunidade acolhedora. Existe também, um ambiente instável, visualizado por um grande número de variáveis que se apresentam, ao mesmo tempo, altamente influentes e também dependentes. A variável de maior influência, na visão do grupo de pesquisa, está no ritmo de trabalho adotado pelas agroindústrias. Dessa forma, o ambiente institucional deve ser aprimorado e iniciar o processo de melhorias, seja no campo das políticas migratórias assim como no desenvolvimento de ações que proporcionem melhor qualidade de vida aos imigrantes e à comunidade local, criando, assim, um ambiente de alta convergência para a integração entre comunidade local e comunidade imigrante. Para que mudanças significativas possam ocorrer é mister, entre outros fatores, que a coordenação do sistema seja impulsionada pelos órgãos institucionais representados pelo governo, com o apoio das agroindústrias em que estes imigrantes trabalham, desenvolvendo alavancas de cooperação mútua entre o governo, indústria e imigrantes. Palavras-Chave: Inserção Social. Imigrantes. Agroindústria. Análise estrutural prospectiva.
\end{abstract}

Abstract: This study presents an analysis of how the institutional, organizational and economic environments can influence the social integration of foreign workers in rondonense community. For this, we applied the Prospective Structural Analysis, a method in the form of matrix analysis of relations between the constituent variables of the system studied and those that belong to their explanatory context. The results suggest that there is a strong influence of the institutional and economic environment regarding immigration policies between countries and social integration of immigrants in the host community. There is also an unstable environment displayed by a large number of variables which arise, while also dependent and highly influential. The variable with the most influence, in view of the research group, is the pace of work adopted by agribusinesses. Thus, the institutional environment must be improved and begin the process of improvement, either in the field of migration policies and the development of actions that provides the best quality of life 
for immigrants and the local community, thus creating an environment of high convergence integration between the local community and the immigrant community. So that significant changes may occur it is necessary, among other things, that the coordination system is driven by institutional bodies represented by the government, with the support of agribusinesses that these immigrants work, developing levers of mutual cooperation between government, industry and immigrants.

Keywords: Social Inclusion. Immigrant., Agribusiness. Prospective structural analysis.

\section{INTRODUÇÃO}

Este estudo tem por objetivo analisar a possibilidade de inserção social dos imigrantes trabalhadores bengaleses (Bangladesh) e senegaleses (Senegal) no Município de Marechal Cândido Rondon - Paraná - Brasil. A questão que o estudo pretende responder está centrada no fato de que, dadas as diferenças na cultura, religião, raça, vida social, renda e língua falada, há condições objetivas de se obter convergência entre o grupo nativo e o grupo de trabalhadores oriundos de outras nações para trabalhar nas agroindústrias avícolas de Marechal Cândido Rondon $\mathrm{PR}$ ?

Para responder essa questão, utilizou-se como técnica de análise a matriz estrutural prospectiva, um método sistemático sob a forma matricial de análise das relações entre as variáveis constitutivas do sistema estudado e aquelas que pertencem ao seu contexto explicativo, fazendo emergir as principais variáveis influentes e dependentes e, desse modo, as variáveis essenciais à evolução do sistema estudado.

A busca por uma resposta se justifica pelo fato de analisar um movimento que vem ocorrendo com maior intensidade nos últimos anos, em que trabalhadores de diversas nações vêm sendo admitidos para trabalharem nas agroindústrias da região. Os estrangeiros, na maioria das vezes, buscam, no Brasil, refúgio por motivos de ameaça, perseguição política, étnica ou religiosa em seu país de origem, além de razões econômicas, como a busca por melhores condições de vida e trabalho. Entretanto, observa-se que existe certa dificuldade para a inserção desses imigrantes nas comunidades em que estão se estabelecendo.

Dessa forma, entender quais os aspectos mais relevantes que podem contribuir para facilitar a inserção desses indivíduos na sociedade, torna-se um fator preponderante.

Estudos realizados nos últimos anos demostram que a maioria dos cidadãos brasileiros considera que os imigrantes, nomeadamente aqueles que são vistos como pertencentes a outras raças, religiões ou culturas, não devem ser discriminados e devem possuir os mesmos direitos que os naturais dos países onde residem e trabalham. Embora exista um discurso dominante no Brasil, que se apresenta como um país tolerante, aberto, com atitudes anti-discriminação, existem também crenças e atitudes preconceituosas, que legitimam comportamentos discriminatórios que ocorrem na vida quotidiana ou em contextos institucionais.

Nesse aspecto, compreender quais as variáveis que exercem maior influência nas relações sociais entre os grupos de imigrantes e a população local, com vistas à inserção desses imigrantes na comunidade rondonense, torna-se um fator relevante quanto ao desenvolvimento cultural e econômico do município, 
uma vez que esses movimentos imigratórios tornam-se uma tendência para o suprimento de mão de obra nas agroindústrias da região.

\section{EMBASAMENTO TEÓRICO}

A integração social pode ser considerada, na visão de Rinus Penninx (2003), citado por Fonseca (2003, p. 108), como um processo de aceitação dos imigrantes pela sociedade receptora, acolhendo-os como indivíduos e como grupos. Nesse processo, existe uma diversidade de intervenientes de integração, como o comportamento dos imigrantes, a atuação do governo, das instituições e da comunidade local.

A palavra "imigração" não é uma palavra neutra e fria, é uma realidade concreta atrelada às pessoas e suas expectativas de vida, de alegrias, esperanças e desejos. Por outro lado, é uma realidade viva, em movimento contínuo que não se deixa fixar nem parar.

Para Pinto (2003), a imigração mais se parece como um puzzle humano colorido, de inumeráveis cores, línguas, sabores, tradições, culturas, religiões. Por isso mesmo, não pede apenas uma resposta, mas respostas variadas e sucessivas, um puzzle que se vai construindo com o esforço de todos. A resposta ao desafio da imigração passa, necessariamente, pelo conhecimento, pelo aprendizado, pela diversidade e a pluridisciplinaridade, as perspectivas diversas, as leis, os regulamentos, os planos, os números, mas, no fundo, é uma questão de humanidade e de coração: reconhecer, ir reconhecendo em cada outro as suas necessidades, a sua plena dignidade, a sua cidadania: reconhecer, para lá das diferenças e com as diferenças, em cada outro uma pessoa, um concidadão e um irmão.

Ao estudar as relações entre os imigrantes e as sociedades de acolhimento, Berry (1990), citado por Vala (2003), propôs um modelo bidimensional sobre o que designa por aculturação. De acordo com o modelo proposto, quando um imigrante se confronta com uma nova sociedade, surgem duas questões básicas: a primeira, quanto à importância de manutenção da identidade cultural do imigrante, e a segunda, quanto à manutenção das relações culturais com outros grupos da sociedade de acolhimento.

As respostas a essas questões configuram-se em quatro modalidades de relações culturais: a integração, que se contextualiza na estratégia de manter aspectos importantes da identidade cultural de origem e, ao mesmo tempo, desenvolver relações com a sociedade de acolhimento, adotando comportamentos e valores dessa sociedade; a separação, que indica um fechamento na cultura de origem; a assimilação, que pelo contrário, indica uma abertura à cultura de acolhimento em detrimento da cultura de origem e, por fim, a marginalização, que não pode ser entendida como estratégia de relação cultural, mas como resultado de um processo de negação da própria cultura e de não integração na cultura da maioria, muitas vezes por rejeição da própria maioria.

Para Andrade (1994, p. 31), o processo de integração de imigrantes estrangeiros pode ser influenciado de várias formas, como as diversidades culturais e políticas, as divergências étnicas, os problemas criados por divergências linguísticas, religião, tradições históricas e culturais. 
Contudo, o ingresso de imigrantes pode expor a sociedade que os recebe a algumas dificuldades de integração social, que podem ser urbanísticas e habitacionais, laborais e familiares ou culturais e linguísticos. Ademais, há o risco da receptividade inicial, motivada pela necessidade do setor produtivo do país que os acolhe, se reverter, em função de crise econômica, iniciando clima de animosidade em relação aos estrangeiros. (FIGURA 1). Nesse sentido, Fonseca (2003) assevera:

Em contextos de crise, os imigrantes, sobretudo os indocumentados, e as minorias étnicas pobres são particularmente afetados, porque são menos qualificados, têm vínculos de trabalho mais precários e, nestes períodos, tendem a aumentar as atitudes discriminatórias e hostis por parte de alguns sectores da população autóctone, que os encaram como potenciais concorrentes no mercado de emprego, ou dos apoios concedidos pelas instituições de segurança social. (FONSECA, 2003, p. 113).

A interação dos diversos vetores de influências da Figura 1 e o modo como evoluem ao longo do tempo explicam a diversidade dos caminhos de incorporação dos diversos grupos de imigrantes que se estabelecem numa determinada cidade em dado momento. A oportuna e apropriada intervenção do sistema político local e a existência e intensidade de preconceitos da sociedade em relação aos imigrantes são elementos decisivos para uma integração bem sucedida. Porém, sem aceitação da sociedade nativa, as políticas de integração podem ser inócuas.

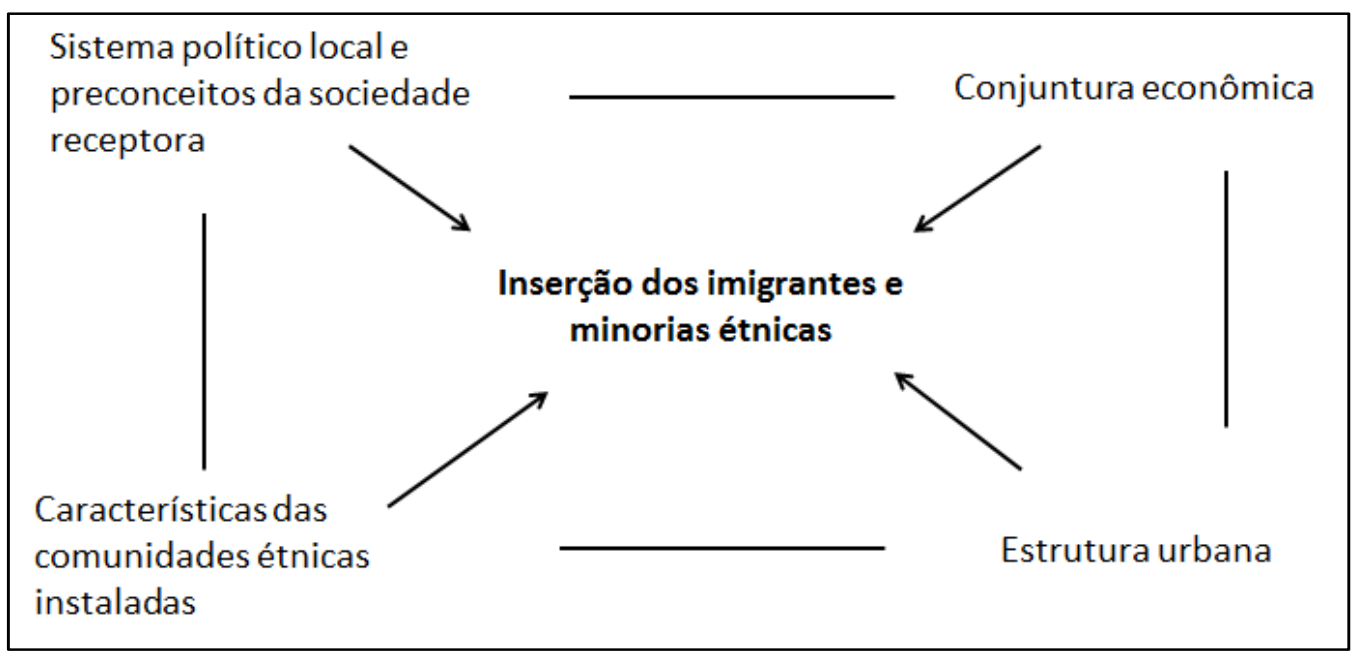

FIGURA 1 - Dimensões estruturantes da integração dos imigrantes nas cidades. Fonte: Adaptado de Fonseca (2003, p. 111).

Por outro lado, os estrangeiros deixam seu país e trabalhos mal remunerados ou, ainda, a ausência de oportunidades de trabalho, na busca por remunerações maiores que permita melhor condição de sobrevivência para si e para seus familiares. Poderão, ainda, almejar algo maior, como implementar negócio próprio em país estrangeiro, sobretudo aqueles com melhor formação (HAESBAERT, 2004).

Nesse processo de interação maior ou menor, os diversos elementos culturais, religiosos, linguísticos, comportamentais poderão interagir de diversos 
modos e intensidades, resultando em elementos mais ricos decorrentes da interação ou diversas possibilidades de separação/marginalização, se esse processo não evoluir adequadamente (VALA, 2003) (FIGURA 2).

Nesse sentido, a integração dos grupos nativo e imigrante demonstra uma estratégia que se traduz em manter elementos importantes da identidade cultural do país de origem e, simultaneamente, construir interações com a sociedade nativa. Por sua vez, a separação indica um fechamento na cultura de origem dos imigrantes. A assimilação sugere uma abertura à cultura nativa em detrimento da cultura de origem. Por último, há o risco da marginalização, a qual não pode ser entendida como estratégia de relação cultural, mas seria resultado da negação da própria cultura e de não integração na cultura nativa local (VALA, 2003).

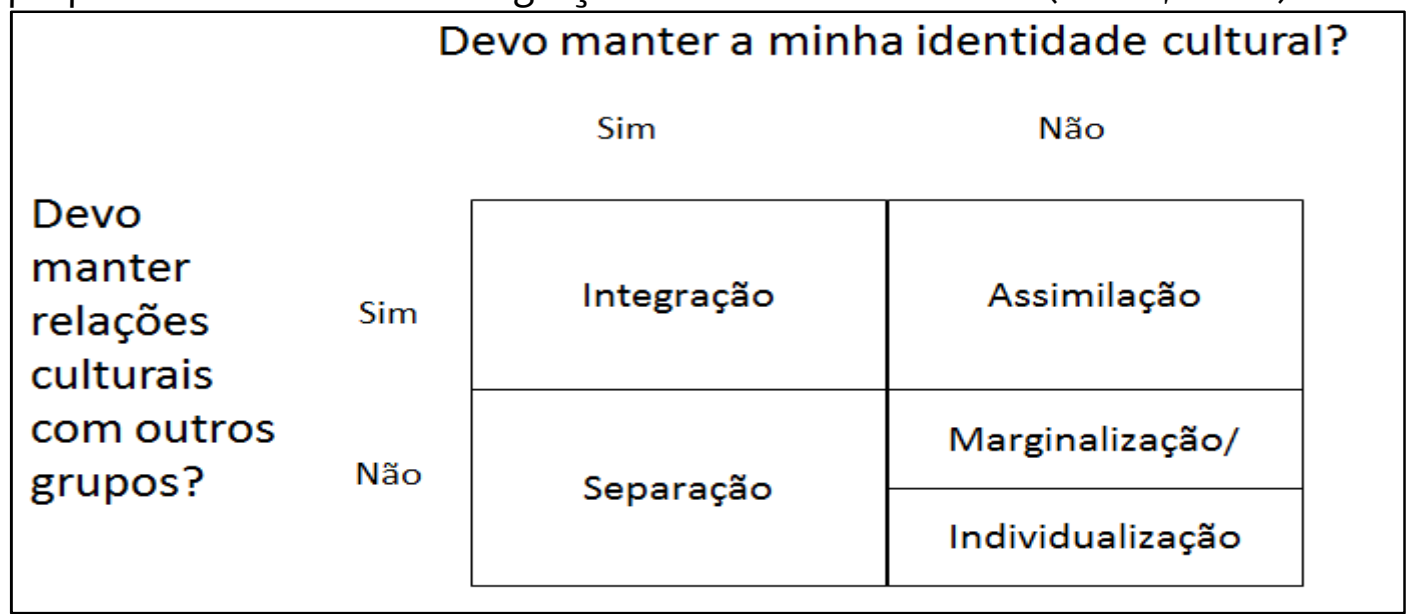

FIGURA 2 - Dimensões estruturantes da integração dos imigrantes nas cidades. Fonte: Adaptado de Vala (2003, p. 51).

Durante o processo de "aproximação" entre o grupo nativo e o estrangeiro, pode existir algum grau de resistência aos elementos culturais, religiosos e outros valores trazidos pelos recém-chegados. Nesse sentido, Milton Santos (1994, p. 16) destaca que "o espaço aparece como um substrato que acolhe o novo, mas resiste às mudanças, guardando o vigor da herança material e cultural, a força do que é criado de dentro e resiste, força tranquila que espera, vigilante, a ocasião e a possibilidade de se levantar". A atuação de instituições, públicas ou não, e o uso de políticas adequadas poderá mitigar eventual movimento nessa direção.

A integração como estratégia de relação cultural supõe que os membros da sociedade de acolhimento olhem para os imigrantes como portadores de uma identidade própria que merece ser respeitada e, simultaneamente, aceitem que estes adotem valores, normas e comportamentos da sociedade de acolhimento. Essa orientação implica que se valorize o biculturalismo, ou o pluriculturalismo, quando se pensa na co-presença de várias comunidades, e que a sociedade de acolhimento se represente ela própria como pluricultural.

Para Cruz (2003), a imigração coloca à sociedade de acolhimento importantes problemas de integração social, quer seja em termos urbanísticos e habitacionais, assim como em termos laborais, familiares, culturais e linguísticos, questões estas que desafiam particularmente a capacidade de planejamento, legislação laboral e sistema de ensino. 
Conforme Papademetriou (2003), a tarefa confrontada hoje ou a ser confrontada nos anos que se seguem é a de gerir uma mudança rápida e profunda, causada apenas parcialmente pela migração internacional. Para gerir, quer a conversação, quer as políticas internas e externas que podem conduzir essa mudança ao benefício das nossas sociedades no longo prazo, necessita-se, acima de tudo, ter mentes mais rígidas, corações mais moles, conciliar melhor as obrigações legais e morais, mais líderes políticos e mais sucessos políticos e administrativos para poder partilhá-los, começando a atingir recordes de desempenho nesta área política tão difícil, mas extremamente necessária.

Se, por um lado, o tema impõe algum "desconforto" para os nativos, a situação dos imigrantes também apresenta certo grau de incerteza, visto que alguma "força" suficientemente forte deve atingi-los para que, mesmo temporariamente, abandonem seu país, família, raízes. Nesse sentido, Bauman (2007) aponta a "vontade de liberdade", que é o esteio da modernidade líquida, a qual se opõe à segurança construída em torno de uma vida social estável, na ordem moderna. Em sua busca, os imigrantes afastam-se dos laços inter-humanos, de sua rede de segurança.

Para Raffestin (1993), os homens vivem, simultaneamente, o processo territorial e o produto territorial por meio de um sistema de interações existenciais e/ou produtivistas. A territorialidade seria um bem constituído pelo conjunto de elementos que ele vive no dia a dia, quais sejam, as interações com o trabalho, com o não trabalho, com o ambiente familiar, com as autoridades políticas ou instituições, dentre outros. No transcorrer dessas interações, esses indivíduos podem adotar "a conduta característica (de um) organismo para tomar posse de um território e defendê-lo contra os membros de sua própria espécie" (RAFFESTIN, 1993, p. 14).

\section{PROCEDIMENTOS METODOLÓGICOS}

A análise estrutural deve ser realizada por um grupo de trabalho composto por pesquisadores e especialistas de domínio considerado. Existem três fases sucessivas que devem ser cumpridas. A primeira fase é o levantamento de todas as variáveis possíveis que interferem no sistema, a segunda, é a identificação das relações existentes entre as variáveis e a terceira e última, é a seleção das variáveis relevantes.

Para a primeira fase deste estudo, efetuou-se um levantamento de possíveis variáveis com base em estudos de materiais relacionados ao tema. Em seguida, essas variáveis foram discutidas pela equipe de coordenação da pesquisa, composto por três professores pesquisadores, um representante dos trabalhadores estrangeiros e quatro acadêmicos, sendo dois do curso de administração e dois do curso de direito. Nessa etapa, os participantes poderiam incluir novas variáveis ou excluir aquelas julgadas menos importantes. De acordo com a definição do grupo, foram estabelecidas e mantidas as variáveis abaixo relacionadas (Quadro 1).

$\mathrm{Na}$ etapa seguinte, o objetivo foi apresentar e discutir as variáveis levantadas na fase anterior. Após a apresentação de todas as variáveis e de uma breve introdução sobre o tema de pesquisa, iniciou-se o preenchimento da matriz estrutural com o grupo de profissionais formado por quatro professores pesquisadores, sendo dois do ISEPE/Rondon e dois da UNIOESTE/Toledo, além do 
grupo representativo da pesquisa, composto por quarenta 45 pessoas, sendo 15 integrantes da comunidade local (empresários, religiosos, militares, políticos e técnicos envolvidos com a temática em estudo), 15 estrangeiros oriundos de Bangladesh e quinze estrangeiros oriundos do Senegal (trabalhadores na agroindústria avícola de Marechal Cândido Rondon).

QUADRO 01 - Variáveis da matriz estrutural prospectiva de ambiente

\begin{tabular}{|c|c|}
\hline $\begin{array}{l}\text { Grupo de } \\
\text { Variáveis }\end{array}$ & Variáveis da Matriz \\
\hline $\begin{array}{l}\text { Ambiente } \\
\text { Organizacional }\end{array}$ & $\begin{array}{l}\text { Relações familiares; Língua falada; Moradia/ Residência; } \\
\text { Sentimento de pertencimento; Religião; Acolhimento pela } \\
\text { comunidade; Desenvolvimento pessoal; Abate Halal; Hábitos } \\
\text { alimentares; Noções de cooperativismo; Tamanho do grupo; }\end{array}$ \\
\hline $\begin{array}{l}\text { Ambiente } \\
\text { Institucional }\end{array}$ & $\begin{array}{l}\text { Políticas migratórias; Legislação; Irregularidades documentais; } \\
\text { Ações sociais (Governo); Benefícios; Relações diplomáticas; } \\
\text { Rota migratória; Burocracia; Políticas do país de origem; } \\
\text { Acordos bilaterais; }\end{array}$ \\
\hline $\begin{array}{l}\text { Ambiente } \\
\text { Econômico }\end{array}$ & $\begin{array}{l}\text { Renda; Cursos de formação/qualificação; Nível de escolaridade; } \\
\text { Formação profissional; Escassez de Mão de Obra; Momento } \\
\text { Econômico (local/origem); Ritmo de trabalho /produtividade; } \\
\text { Quantidade de empresas interessadas; Oportunidade de } \\
\text { carreira; Situação financeira; Competitividade / trabalho. }\end{array}$ \\
\hline
\end{tabular}

QUADRO 01 - Variáveis da matriz estrutural prospectiva de ambiente.

Fonte: Dados da Pesquisa.

Para tornar mais ampla e abrangente a discussão acerca das relações de influência entre as variáveis a serem analisadas, o grupo foi dividido em seis subgrupos de sete ou oito integrantes. No entanto, em razão das diferenças de língua falada, foi necessário a presença de um tradutor/intérprete, para intermediar as discussões.

Nessa etapa, para cada par de variáveis, atribuiu-se a seguinte questão: existe uma relação de influência direta entre a variável ie a variável $\int$ ?

Nos casos em que as respostas fossem negativas, solicitou-se aos respondentes que atribuíssem nota (0). Nos casos em que as respostas fossem positivas, solicitou-se que atribuíssem notas em função do grau de influência direta, conforme a percepção dos respondentes, ou seja, nota (1) se considerada influência fraca; nota (2) se considerada média influência; nota (3) se a influência for considerada forte.

Para a construção da matriz estrutural prospectiva, utilizou-se a forma quadrática, em que as variáveis são confrontadas com elas mesmas, tendo resultado de dupla entrada em linha e em coluna, formando-se, assim, uma matriz de 32 linhas e 32 colunas (32×32), conforme modelo apresentado no Quadro 2. As 32 linhas e colunas da matriz são resultado da quantidade de variáveis previamente definidas.

Para o preenchimento da matriz, verificou-se a incidência da variável linha ' $i$ ' sobre a variável coluna ' $j$ ', ficando a diagonal principal sem preenchimento, em razão de não ser possível fazer a análise de influência da variável sobre ela mesma. 
Sendo assim, a pesquisa delineada como qualitativa, passa a possuir, também, um caráter quantitativo. No caso da matriz quadrática aplicada neste estudo ( $32 \times 32)$, são estabelecidos 1024 resultados de avaliação. ${ }^{1}$

$\mathrm{Na}$ sequência, realizou-se a identificação das variáveis através de uma classificação direta, de fácil realização. Em seguida, através de uma classificação indireta, por meio da utilização do aplicativo "Matriz de Impactos Cruzados Multiplicações Aplicadas a uma Classificação" - MICMAC. Essa classificação indireta é obtida após elevação à potência da matriz inicial.

QUADRO 2 - Representação genérica da matriz estrutural prospectiva.

\begin{tabular}{|c|c|c|c|c|c|c|c|}
\hline$j$ & 1 & 2 & 3 & 4 & 5 & $\ldots$ & 32 \\
\hline 1 & & 2 & 0 & 1 & 4 & & \\
\hline 2 & 2 & & 1 & 2 & 0 & & \\
\hline 3 & 1 & 3 & & 2 & 1 & & \\
\hline 4 & 4 & 0 & 4 & & 0 & & \\
\hline 5 & 3 & 1 & 3 & 2 & & & \\
\hline$\ldots$ & & & & & & & \\
\hline 32 & & & & & & & \\
\hline
\end{tabular}

QUADRO 2 - Representação genérica da matriz estrutural prospectiva.

Fonte: Elaboração dos autores.

A comparação da hierarquia das variáveis nas diferentes classificações (direta, indireta e potencial) é rica em ensinamentos. Ela permite confirmar a importância de certas variáveis e também revelar variáveis que, em virtude das suas ações indiretas, desempenham um papel preponderante e que a classificação direta não permite detectar.

Os resultados anteriormente referidos, em termos de influência e de dependência de cada variável, deverão ser representados sobre um plano axial em que o eixo das abscissas corresponde à dependência e o eixo das ordenadas à influência (Figura 3). Assim, para além da identificação das variáveis mais influentes do sistema estudado, pode existir interesse pelas diferentes funções das variáveis no sistema.

Segundo Godet e Durance (2011), as variáveis podem ser colocadas nesse plano para fornecerem as relações diretas, indiretas e potenciais, de acordo com cada um dos setores onde as variáveis estiverem localizadas.

No quadrante (1), encontram-se as variáveis de entrada, consideradas influentes e pouco dependentes, elas são as variáveis explicativas e condicionam todo o sistema, sendo objeto de ações prioritárias. No quadrante (2) localizam-se

\footnotetext{
${ }^{1}$ Cálculo: $(32$ X 32) = 1024, menos os resultados da diagonal principal, que representam o confronto da variável com ela mesma, ou seja, menos 32, o que leva a 992 resultados de inter-relações.
} 
as variáveis de ligação, que são, ao mesmo tempo, muito influentes e muito dependentes. Elas são por natureza, muito instáveis, assim, qualquer ação sobre essas variáveis repercutirá sobre as demais e também sobre elas mesmas, modificando toda a dinâmica global do sistema.

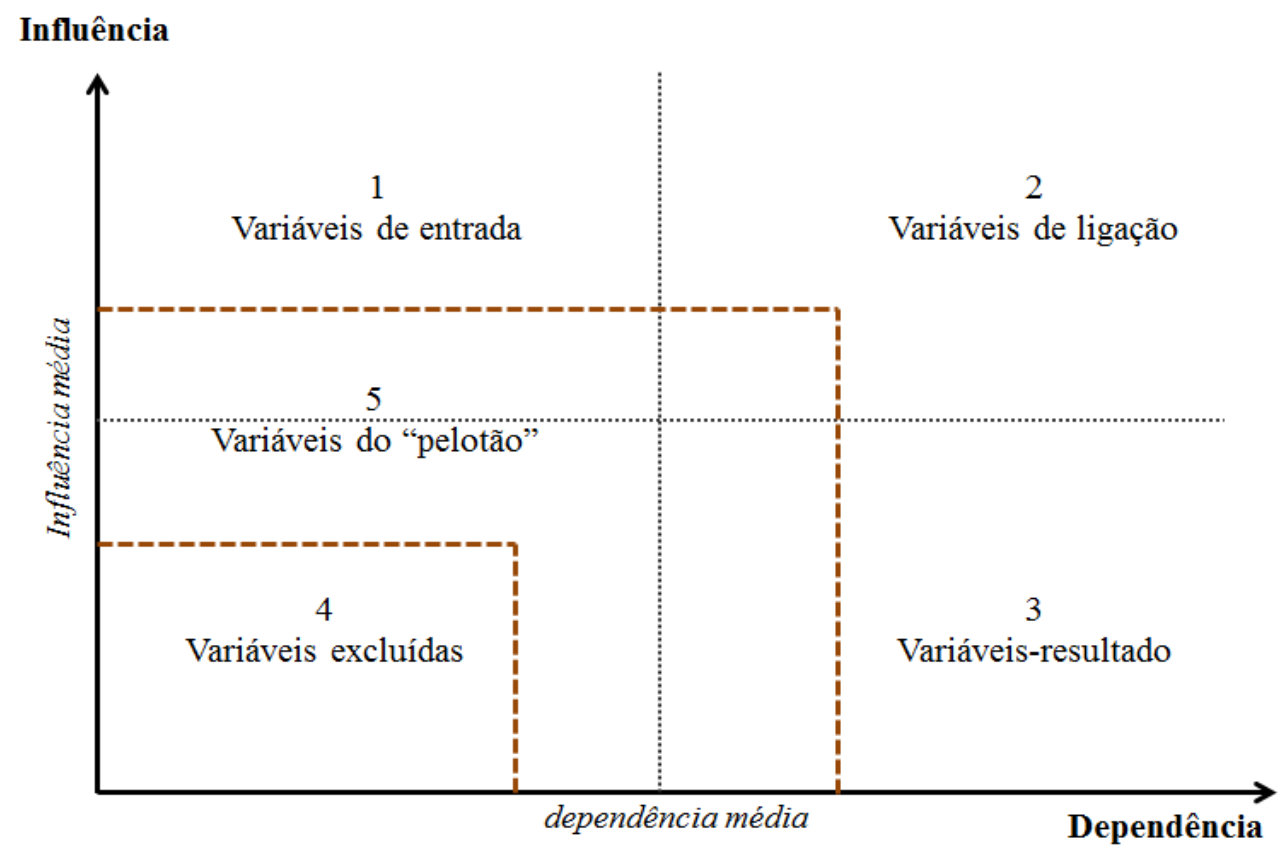

FIGURA 3 - Os diferentes tipos de variáveis sobre o plano de influência e de dependência.

Fonte: Godet e Durance (2011).

No quadrante (3), estão posicionadas as variáveis - resultado, que são pouco influentes e muito dependentes. Sua evolução explica-se pelos impactos provenientes de outras variáveis, principalmente das variáveis presentes nos quadrantes (1) e (2). As variáveis do quadrante (4) são variáveis pouco dependentes e pouco influentes, e devem ser desconsideradas do sistema pelas suas poucas ligações com as demais variáveis. $E$, finalmente, existe uma quinta área (5) em que estão inseridas as variáveis denominadas de "variáveis-pelotão".

Essa área é delimitada pela variação do desvio-padrão dos valores estabilizados que compõem as influências e dependências. Em relação às variáveis contidas nesse setor, a princípio nada se pode dizer. Elas devem receber um tratamento mais detalhado para que alguma inferência seja feita sobre elas.

De acordo com Godet e Durance (2011), um dos motivos de interesse da análise estrutural consiste em permitir a verificação das hipóteses formuladas por um grupo sobre a explicação do funcionamento do sistema.

De fato, ela ajuda a confirmar se as variáveis julgadas importantes são explicativas (variáveis de entrada) ou explicadas por outras (variáveis - resultado); sendo certo que as medidas e os efeitos sobre o sistema não são os mesmos.

Muitas vezes, os resultados de uma análise estrutural são surpreendentes: entre $10 \%$ e $20 \%$ desses resultados são contraintuitivos. Eles revelam relações cuja evidência está a priori ausente ou, ainda, conduzem a atribuir a certas variáveis uma influência, ou uma dependência, superior ou inferior ao previsto. 


\section{RESULTADOS E DISCUSSÃO}

Os resultados apresentados nesta sessão são provenientes do levantamento realizado por meio da utilização da matriz de 32 variáveis aplicadas ao estudo e classificadas em três grandes grupos, compostos pelos ambientes organizacional, institucional e econômico, existindo para cada ambiente um conjunto de variáveis associadas.

$\mathrm{Na}$ avaliação das variáveis, considera-se, além da classificação quanto ao nível de influência, o posicionamento delas no mapa de influências e dependências (Figura 3), gerado pelo aplicativo MICMAC (Matriz de Impactos Cruzados Multiplicações Aplicadas a uma Classificação), além do reposicionamento dessas variáveis quando elas sofrem os impactos referentes ao cruzamento das variáveis, formando uma nova classificação, obtida por influências indiretas, coluna MII da Figura 4.

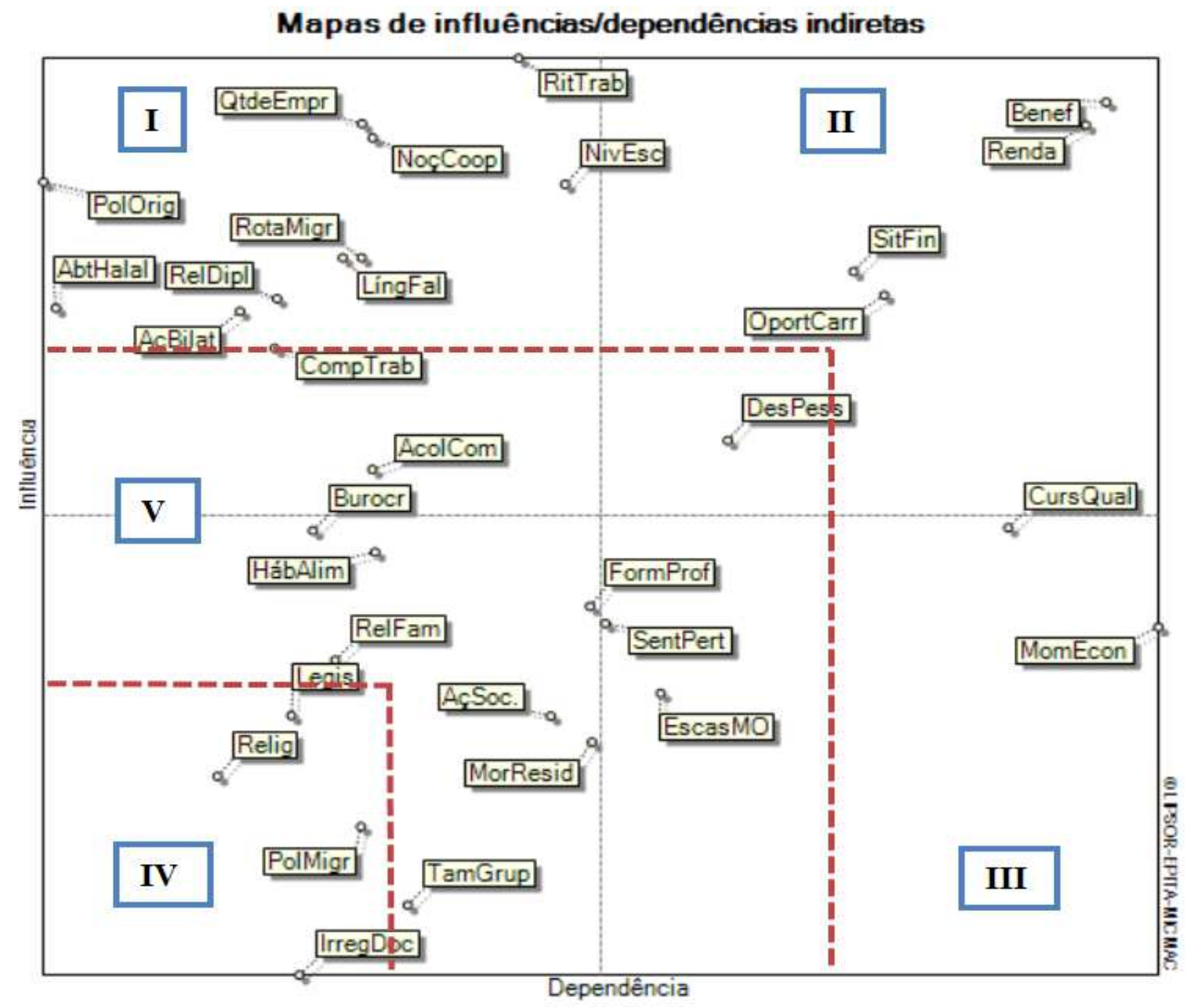

FIGURA 4 - Mapa de Influências e Dependências Indiretas.

Fonte: Dados da Pesquisa.

Com base no mapa de influências e dependências indiretas (figura 3), pode-se observar que, no quadrante (I), encontra-se um conjunto de dez variáveis, consideradas como variáveis de entrada, ou seja, altamente influentes e pouco dependentes. Essas variáveis são consideradas como explicativas, pois condicionam todo o sistema e devem ser objeto de ações prioritárias.

Dessas dez variáveis, 40\% estão relacionadas ao ambiente institucional, o qual possui um enfoque macroanalítico em que as variáveis (rota migratória, 
políticas do país de origem, acordos bilaterais e relações diplomáticas) se relacionam com a política, a legislação e as instituições que formam e estruturam os aparatos regimentais de uma sociedade.

Nesse aspecto, os resultados do estudo apontam, como ações prioritárias, a necessidade de desenvolvimento de políticas públicas que facilitem o processo de imigração, melhorando o acesso desses trabalhadores ao país de destino, além do estabelecimento de acordos bilaterais e relações diplomáticas entre ambos os países, ou seja, criar um fluxo de informações que torne o processo migratório menos burocrático e que exista uma estrutura de apoio para a recepção desses imigrantes quando da sua chegada ao país.

Esse fluxo de informações pode ser desenvolvido de forma conjunta, entre ambos os países, por meio de políticas bem elaboradas. O sentimento do grupo é que o governo precisa interferir, dentro da esfera política, com medidas eficazes que venham a contribuir para a agilidade e melhorarias no processo de imigração, possibilitando que os imigrantes sejam acolhidos no país de destino e ali encontrem possibilidades de crescimento pessoal e profissional, desenvolvimento e uma qualidade de vida mais digna e justa.

Observando o quadrante (II) do mapa de influências e dependências, identifica-se que as variáveis de ligação, que são ao mesmo tempo muito influentes e muito dependentes, relacionam-se significativamente ao ambiente econômico. As variáveis que se enquadram nesse setor do mapa são: renda, situação financeira e oportunidade de carreira (ambiente econômico) e benefícios oferecidos pelo governo local (ambiente institucional). Nesse aspecto, os resultados do estudo demonstram claramente que os principais atrativos para a inserção desses trabalhadores na comunidade rondonense estão centrados na busca por uma qualidade de vida melhor. Assim, tem-se a busca da "modernidade líquida" de Bauman (2007).

Entretanto, visualiza-se, nessa área do mapa, certa instabilidade (alta influência e alta dependência), ou seja, o desejo de uma condição melhor de vida exerce influência nas decisões desses imigrantes ao chegarem ao local. Entretanto, o sucesso dessa condição depende em muito dos níveis de empregabilidade e sociabilidade que estes encontrarão nas sociedades em que serão acolhidos, nos moldes de Fonseca (2003).

Já no quadrante (III), localizam-se as variáveis-resultado, (cursos de qualificação e momento econômico). Essas são consideradas pouco influentes, porém muito dependentes. Isso demonstra que os respondentes avaliam que a qualificação profissional dos imigrantes, assim como o momento econômico vivenciado por eles no país de destino são extremamente dependentes da evolução das demais variáveis que se encontram nos quadrantes (I) e (II), ou seja, faz-se necessário o estabelecimento de ações que proporcionem melhorias nessas variáveis, causando, assim, os impactos necessários nas variáveis localizadas no quadrante (III).

Com relação às variáveis situadas nos quadrantes (IV): legislação, política migratória, religião e irregularidade documental não exercem forte influência e dependência ao se relacionarem com as demais variáveis do sistema, devendo ser desconsideradas no processo de ações prioritárias. Isso pode estar associado ao fato de que, mesmo não estando devidamente regularizados no país, os imigrantes têm conseguido estabelecer relações de emprego e uma condição de vida melhor 
do que aquela vivenciada em seu país de origem, dando-lhes uma sensação de estabilidade perante a sociedade na qual foram acolhidos, alinhando-se às ideias de Bauman (2007). Ressalta-se que o fato dos imigrantes possuírem Carteira de Trabalho e Previdência Social (CTPS) Ihes proporciona o direito de trabalhar e os mesmos benefícios dos trabalhadores brasileiros, constituindo elementos semelhantes àqueles apontados por Raffestin (1993) e Haesbaert (2004).

Em relação à variável religião, a baixa representatividade pode estar associada ao fato de que mesmo não existindo mesquitas (igrejas) para o cumprimento do dever religioso dos imigrantes no Município de Marechal Cândido Rondon, estes conseguem fazer suas orações normalmente em função de se reunirem em grupos (tipo de moradia escolhida pelos imigrantes) e, também, pelo fato de que exercem sua religiosidade até mesmo no trabalho ao executarem o processo de abate halal (variável 8) nos frigoríficos em que trabalham.

Sobre as variáveis localizadas no quadrante (V), consideradas como variáveis "pelotão", nenhuma inferência pode ser feita sem um tratamento mais detalhado. Das doze variáveis localizadas nesse setor, sete estão associadas ao ambiente organizacional, como acolhimento da comunidade, hábitos alimentares, relações familiares, desenvolvimento pessoal, sentimento de pertencimento, moradia/residência e tamanho dos grupos, conforme ideias de Raffestin (1993).

Dessas variáveis, esperava-se que algumas apresentassem forte influência, como hábitos alimentares, relações familiares e acolhimento da comunidade, uma vez que existem amplas diferenças culturais e de religião entre os imigrantes e a comunidade local. No entanto, os resultados da pesquisa não enfatizaram de forma significativa essas nuances.

Em relação à classificação das variáveis em função das influências, pode-se avaliar o comportamento de cada variável mediante uma observação acerca da Figura 5 a seguir. Nessa, apresenta-se o posicionamento das variáveis por ordem de influência, sendo na primeira coluna classificadas as variáveis de acordo com as influências diretas e na segunda coluna, as influências indiretas.

Para uma melhor análise, essas colunas foram divididas em outros três níveis de classificação, sendo consideradas de alta influência as variáveis relacionadas da $1^{\mathrm{a}}$ a $10^{\mathrm{a}}$ posição, de moderada influência as variáveis relacionadas entre a $11^{a}$ e $20^{a}$ posição e, por fim, de baixa influência as variáveis posicionadas entre a $21^{\mathrm{a}}$ e $32^{\mathrm{a}}$ colocação. 


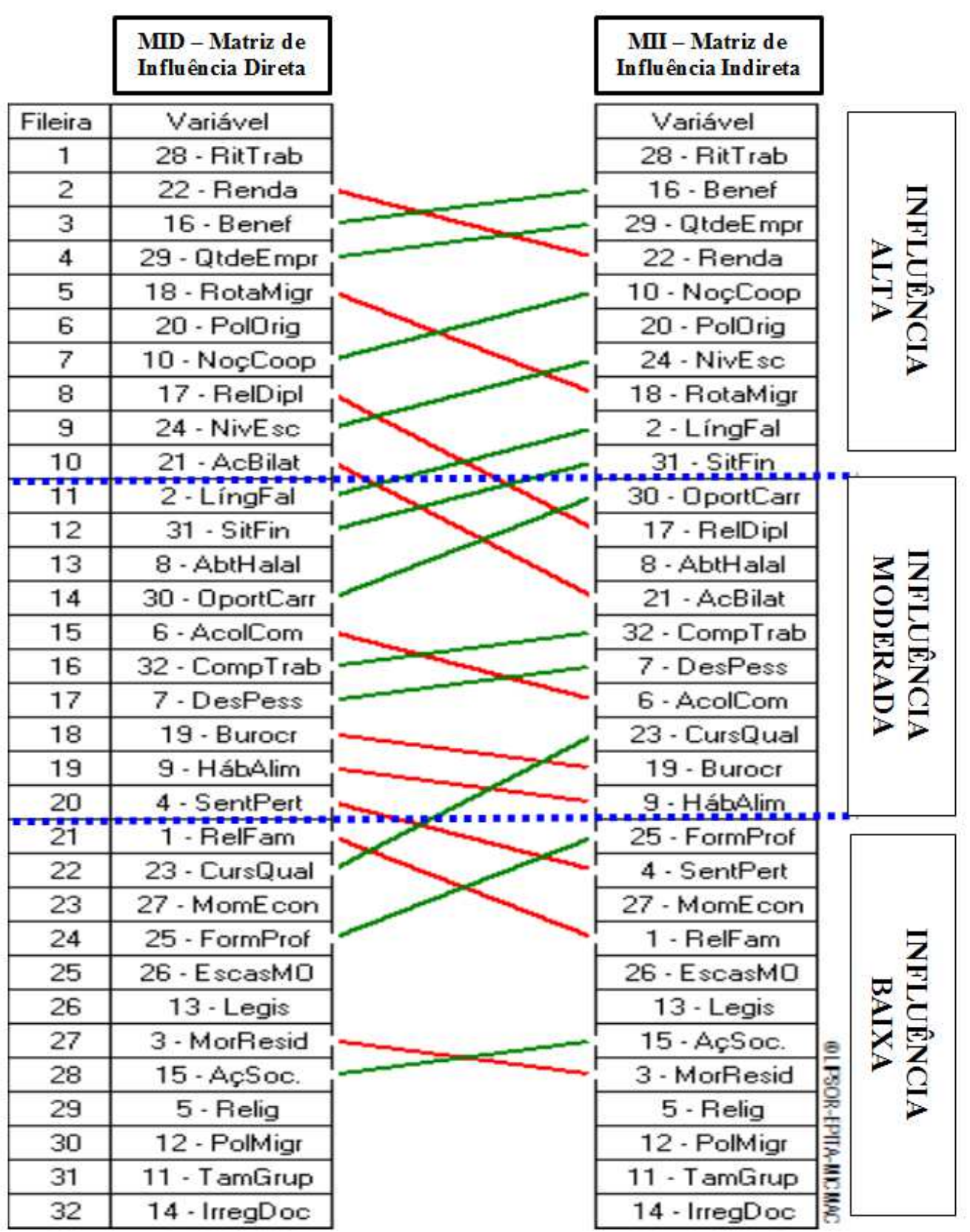

FIGURA 5 - Classificação das Variáveis por Influência.

Fonte: Dados da Pesquisa.

Nota: as linhas que conectam as duas colunas principais (MID e MII) representam o posicionamento das variáveis de acordo com o grau de influência, onde as linhas descendentes exprimem a queda de posicionamento original e as ascendentes, a elevação no seu posicionamento.

Sob essa ótica, pode-se observar que a variável mais influente é representada pelo ritmo de trabalho, ou seja, o nível de desempenho exigido pelas empresas aos trabalhadores imigrantes em comparação com os mesmos profissionais nativos e/ou comparação com o ritmo de trabalho em seu país de origem. Essa alta influência pode ser explicada pela modalidade de atividade escolhida pelos imigrantes para o desempenho profissional, a agroindústria avícola, que possui um sistema de trabalho extremamente complexo, atividades repetitivas e de grandes volumes de produção, atividade à qual, provavelmente, não estavam 
acostumados nos país de origem. No entanto, esses profissionais são bastante requisitados em razão de uma exigência dos países exportadores da carne de frango brasileira, sob os preceitos do ritual de abate islâmico, nos moldes de Raffestin (1993).

Essa mesma variável, também está localizada no quadrante (I) do mapa de influências e dependências, significando que, na visão dos respondentes, deve ser alvo de ações prioritárias, ou seja, as agroindústrias devem se atentar para melhorar as condições, no que tange ao ritmo de trabalho desenvolvido nas agroindústrias brasileiras, medidas essas muito discutidas pelas classes sindicais da categoria profissional.

A segunda variável mais influente é a renda dos profissionais, representada pela contrapartida recebida pelos imigrantes em prol dos serviços prestados às agroindústrias, os quais sentem que deveriam ser melhor remunerados pelas atividades que executam. Entretanto, esta variável muda de posição, saindo da $2^{a}$ ordem de classificação para a $4^{a}$ posição ao interagir indiretamente com as demais variáveis.

E, nessa situação, a vaiável 16 (benefícios), que ocupa a segunda posição, é compreendida pelos aportes benéficos ofertados aos funcionários das empresas em forma de alimentação; plano de saúde; moradia; transporte; auxilio odontológico; entre outros, que, na visão dos imigrantes e demais respondentes, exercem forte influência e facilitam a inserção dos imigrantes no meio social do município rondonense.

A quantidade de empresas interessadas em contratar mão de obra estrangeira apresenta-se na terceira posição entre as variáveis mais influentes, demonstrando que quanto mais empresas interessadas tiverem, maior poderá ser o fluxo migratório entre essas nações, principalmente, havendo apoio e incentivos por parte do governo e, por consequência, quanto maior o volume de imigrantes, maior as possibilidades de se fixarem e criarem raízes nas comunidades que os acolhem, em alinhamento a Fonseca (2003).

Por outro lado, considerando a classificação das variáveis em função das dependências, assim como é possível visualizar no mapa (Figura 5), nota-se que a variável mais dependente é o momento econômico, ou seja, a decisão de migrar para outra localidade está devidamente associada ao momento econômico vivenciado tanto pelo país de origem quanto pelo país de destino. O que os imigrantes buscam é a fuga de um país que não oferece boas condições e qualidade de vida para então suprir essas necessidades em outras localidades, ou seja, outras nações.

Em seguida, as variáveis, benefício e renda, discutidas anteriormente como altamente influentes, aparecem também, como altamente dependentes, ou seja, estas variáveis são o alvo em busca de uma melhor qualidade de vida e, ao mesmo tempo, fator preponderante na decisão de permanência no local, pois, se o objetivo não é alcançado, pode não motivar os imigrantes ao estabelecimento de uma relação mais duradoura na comunidade escolhida para sobreviver.

\section{CONSIDERAÇÕES FINAIS}

Este estudo buscou analisar como os ambientes institucional, organizacional e econômico podem influenciar na inserção social de trabalhadores 
estrangeiros na comunidade rondonense. Com base na avaliação obtida por meio da interpretação dos mapas resultado da pesquisa, obtidos por meio da aplicação da técnica de análise por matriz estrutural prospectiva, considera-se possível obter convergência entre o grupo nativo e o grupo de trabalhadores oriundos de outras nações para trabalhar nas agroindústrias avícolas de Marechal Cândido Rondon PR.

Para tanto, são necessárias algumas ações prioritárias, na visão do grupo composto pelos 15 representantes da comunidade rondonense e pelos 30 representantes da comunidade estrangeira, sendo 15 imigrantes oriundos de Bangladesh e 15 do Senegal.

Essas ações apontam para a necessidade de desenvolvimento de políticas públicas que facilitem o processo migratório, melhorando o acesso desses trabalhadores ao país de destino, além do estabelecimento de acordos bilaterais e relações diplomáticas entre ambos os países, ou seja, a existência de um fluxo de informações que torne o processo migratório menos burocrático e que exista uma estrutura de apoio para a recepção desses imigrantes quando da sua chegada ao país. Esse fluxo de informações pode ser desenvolvido de forma conjunta, entre ambos os países, por meio de políticas bem elaboradas e bem estruturadas.

O sentimento do grupo é que o governo precisa interferir, dentro da esfera política, com medidas eficazes que venham a contribuir para a agilidade e melhorias no processo de imigração, possibilitando, assim, que os imigrantes sejam bem acolhidos no país de destino e ali encontrem possibilidades de crescimento pessoal e profissional, desenvolvimento e uma qualidade de vida mais digna e justa. Os imigrantes não se sentem mal acolhidos, entretanto, sentem a necessidade de um processo mais eficiente no que tange às políticas de imigração estabelecidas entre os países, as quais poderiam facilitar substancialmente o processo migratório.

Por outro lado, também sentem que as empresas deveriam se atentar para melhores condições no que tange ao ritmo de trabalho desenvolvido nas agroindústrias brasileiras, medidas essas muito discutidas pelas classes sindicais da

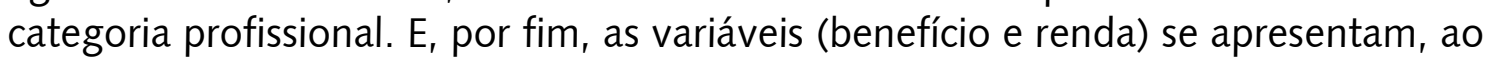
mesmo tempo, como altamente influentes e também dependentes, ou seja, são alvo na busca por melhor qualidade de vida e, ao mesmo tempo é fator preponderante na decisão de permanência no local, pois, se o objetivo não é alcançado pode não motivar os imigrantes ao estabelecimento de uma relação mais duradoura na comunidade escolhida para sobreviver.

Os resultados apontaram certa homogeneidade com os conceitos teóricos propostos nesta pesquisa. Na visão de Fonseca (2003), os imigrantes tiveram seus deslocamentos de fronteira por motivos de crise em seus territórios de origem. Isso evidenciaria, na concepção de Raffestin (1993), que os imigrantes tiveram um sistema de perda de território, ou seja, são desterritorializados na cidade de Marechal Cândido Rondon.

Nessa mesma ótica, Bauman (2007) indica para essa imigração um tempo de modernidade líquida em que, por analogia, a interação de novos sujeitos na comunidade local é bem vinda na organização da produção da indústria, sob a forma de trabalho de baixa qualificação. Todavia, esses sujeitos ainda são tratados como "estranhos". 
Por fim, há uma garantia da interação e inserção desses imigrantes no espaço territorial de Marechal Cândido Rondon decorrente das ações da matriz institucional federal e da comunidade local. Para esses imigrantes, há um sentimento de pertencimento à comunidade local.

\section{REFERÊNCIAS}

ANDRADE, M. Corrêa - Territorialidades, Desterritorialidades, Novas Territorialidades: Os Limites do Poder Nacional e do Poder Local. In: SANTOS, Milton, Maria Adélia A., SILVEIRA, Maria Laura. Território, Globalização e Fragmentação. São Paulo: Editora Hucitec/ ANPUR, 1994, p. 213-220.

BAUMAN, Z. Tempos líquidos. Tradução de Carlos Alberto Medeiros. Rio de Janeiro: Jorge Zahar, 2007.

CRUZ, M. B. Sessão de Abertura. IN: Actas do I Congresso Imigração em Portugal: Diversidade-Cidadania-Integração. [Org.] Alto Comissariado para a Imigração e Minorias Étnicas. Lisboa: ACIME, 2003.

FONSECA, M. L. Dinâmicas de integração dos imigrantes: estratégias e protagonistas. IN: ACIME - Alto Comissariado para a Imigração e Minorias Étnicas (Org.). I Congresso Imigração em Portugal [Diversidade - Cidadania - Integração]. Actas do I Congresso Imigração em Portugal: Diversidade-Cidadania-Integração. Lisboa: ACIME, 2003. p. 108-150.

GODET, M.; DURANCE, P. A prospectiva estratégica: para as empresas e os territórios. Paris: Dunod, 2011.

HAESBAERT, R. O mito da desterritorialização: do "fim dos territórios" à multiterritorialidade. Rio de Janeiro: Bertrand Brasil, 2004.

PAPADEMETRIOU, D. IN: Actas do I Congresso Imigração em Portugal: Diversidade-Cidadania-Integração. [Org.] Alto Comissariado para a Imigração e Minorias Étnicas. Lisboa: ACIME, 2003.

PINTO, A. V. Sessão de Abertura. IN: Actas do I Congresso Imigração em Portugal: Diversidade-Cidadania-Integração. [Org.] Alto Comissariado para a Imigração e Minorias Étnicas. Lisboa: ACIME, 2003.

RAFFESTIN, C. Por uma geografia do poder. Tradução de Maria Cecília França. São Paulo: Ática, 1993.

SANTOS, M. A aceleração contemporânea: tempo-mundo e espaço-mundo. IN: Técnica, espaço, tempo: globalização e meio técnico-científico informacional. São Paulo: Hucitec, 1994. p. 12-17.

VALA, J. Processos identitários e gestão da diversidade. IN: ACIME - Alto Comissariado para a Imigração e Minorias Étnicas (Org.). I Congresso Imigração em Portugal [Diversidade - Cidadania - Integração]. Actas do I Congresso Imigração em Portugal: Diversidade-Cidadania-Integração. Lisboa: ACIME, 2003. p. 48-72.

Submetido em: 01/04/2015.

Aprovado em: 14/10/2015.

Sobre os autores

Paulo César da Silva llha 
Doutor e Mestre em Desenvolvimento Regional e Agronegócio pela Universidade Estadual do Oeste do Paraná - UNIOESTE/Campus de Toledo - PR. Especialista em Administração de Cooperativas. Especialista em Marketing. Administrador de Empresas. Tecnólogo em Cooperativismo. Atualmente é professor e coordenador do curso de Administração do ISEPE/Marechal Cândido Rondon - PR.

Endereço: Rua Sete de Setembro 2441, Alvorada. 85960-000 - Marechal Cândido Rondon, PR, Brasil

E-mail: paulocesarilha@yahoo.com.br

\section{Valdir Antonio Galante}

Doutorando em Desenvolvimento Regional e Agronegócio da Universidade Estadual do Oeste do Paraná (UNIOESTE/Toledo), Mestre em Economia Rural pela Universidade Federal do Ceará - UFC, Professor Assistente do Curso de Ciências Econômicas da UNIOESTE/Toledo.

Endereço: Rua da Faculdade, 645, Santa Maria. 85903-000 - Toledo, PR, Brasil.

E-mail:vgalante@hotmail.com

\section{Manoel João Ramos}

Doutorado em andamento em Recursos Pesqueiros e Engenharia de Pesca - Universidade Estadual do Oeste do Paraná - UNIOESTE. Mestre em Desenvolvimento Regional e Agronegócio pela Universidade Estadual do Oeste do Paraná - UNIOESTE. Professor e coordenador do curso de Engenharia de Produção do ISEPE/Marechal Cândido Rondon-PR.

Endereço: Rua Sete de Setembro, 2341, Jardim Alvorada. 85960-000 - Marechal Cândido Rondon, $P R$, Brasil.

E-mail: eng.major@hotmail.com

\section{Moacir Piffer}

Doutor em Desenvolvimento Regional pela Universidade de Santa Cruz do Sul, RS. Professor adjunto da Universidade Estadual do Oeste do Paraná, colegiado de Ciências Econômicas. Membro do grupo de pesquisa GEPEC. Professor do Programa Pós-Graduação em Desenvolvimento Regional e Agronegócio (PGDRA).

Endereço: Rua da Faculdade, 645, Jd. La Salle. 85903-000 - Toledo, PR, Brasil.

E-mail:mopiffer@yahoo.com.br 